\section{A constituição da pesquisa em poéticas visuais a partir de uma experiência pessoal de ateliê}

The constitution of research in visual poetics through personal studio experience

Resumo: Este artigo propõe-se como uma reflexão a partir das investigações que foram empreendidas durante Estágio Pós-Doutoral, em meio ao processo pictórico que elaborei enquanto artista/pesquisador na linha de Poéticas Visuais. A premissa foi a de que a pesquisa nesta linha deve contemplar os meandros de sua própria construção. Ou seja, estudos e análises são guiados pelos desdobramentos do trabalho de ateliê e, simultaneamente, fornecem os parâmetros para a continuidade desse próprio processo

Pesquisado

Abstract: This article proposes critical reflection about the investigations that were carried out during my postdoctoral research course [internship], in which I developed my pictorial process as an artist/researcher in the line of research visual poe tics. This line is based on the premise that such research considers the intricacies tics. This line is based on the premise that such research considers the intricacies unfolding of the studio work which, simultaneously, supplies the parameters for the continuation of the process itself.

Key words: Visual poetics; painting; contemporary art; poietics; artist/researcher
A partir da contínua investigação quanto aos princípios daquilo que pode contemplar uma pesquisa acadêmica de processos de criação e atuação em artes visuais, desenvolvi ao longo de meu Estágio Pós-Doutoral um processo pictórico específico que elaborei na condição de artista/pesquisador em Poéticas Visuais, no PPGARTES (Programa de Pós-Graduação em Artes) da UFPA (Universidade Federal do Pará) em Belém do Pará (MELLO, 2016).

Após minhas pesquisas de mestrado (MELLO, 2008) e doutorado (MELLO, 2013) na linha de Poéticas Visuais do PPGAV (Programa de Pós-Graduação em Artes Visuais) da UFRGS (Universidade Federal do Rio Grande do Sull), o problema que se colocou para minha pesquisa de pós-doutorado (que se deu entre maio de 2015 e abril de 2016) foi o de buscar ainda um outro adensamento conceitual dos processos elaborados em ateliê. A proposta de pesquisa foi então a de se trabaIhar de forma crítica e sistemática uma produção em pintura com pequenos formatos que reelaborava manual e minuciosamente imagens oriundas do cinema, captadas do vídeo analógico através da fotografia

Tal proposta operou nos vieses que a universidade dispõe ao artista como caminho para existir e para dar existência ao seu trabalho, conforme pôde se perceber ao longo das últimas décadas. Isto no sentido de criar, elaborar, refletir e manifestar essa produção, o que comumente se dá através da linha de pesquisa que é identificada como Poéticas Visuais.

No campo das Artes Visuais, a passagem histórica do século XIX para o século XX presenciou uma situação cada vez mais plena de liberdade do artista em termos de autonomia e inserção social. No decorrer do século XX - especialmente ao longo das décadas de 50 a 70 -, a figura do artista busca afirmar e construir gradual e fundamentalmente uma independência para si como cidadão e para a sua produção em termos autorais.

Tal condição foi alcançada não apenas no que diz respeito às temáticas que são abordadas pelos artistas, mas mesmo nas próprias estruturas do que compõe o objeto de arte e por quais meandros este se 
manifesta. Como é o caso de artistas relacionados ao movimento da Arte Conceitual, tais como Joseph Kosuth e os artistas pertencentes ao Grupo Fluxus, que definiram e estabeleceram para si estratégias de trabalho, produção e atuação que desmaterializavam o objeto de arte e prescindiam até mesmo do mercado de arte para existir e se manifestar, buscando outros modos de inserção e circulação (WOOD, 2002).

Joseph Beuys, artista relacionado ao Grupo Fluxus e aos seus modos de prática e existência, teve como parte importante e indissociável de seu trabalho de arte sua atuação como professor - seja por vias informais, como performances ou na academia de artes Kunstakademie Düsseldorf (entre 1961 e 1972). Beuys entendia mesmo que a prática pedagógica era um dos modos mais pertinentes de manifestação da arte (Figura 1).

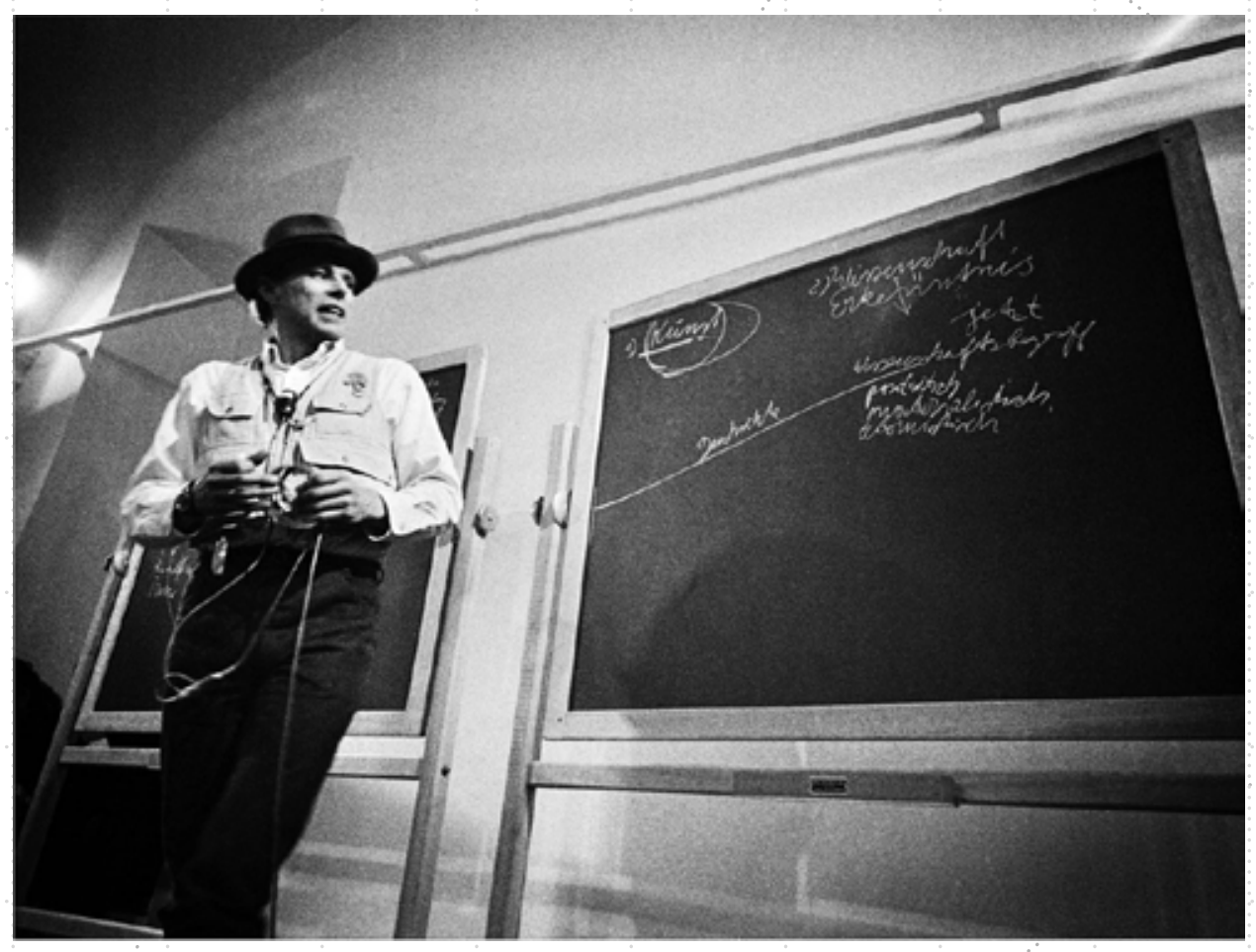

Figura 1. Joseph Beuys lecionando no School of

the Art Institute of Chicago, 1974

Fonte: http://eng.johanandlevi.com/admin/

imgsupl/SNP1383731021_695_immagini_della_ galleria_immagine_18.jpg.
Também no Brasil compartilhamentos de trabalho e agrupamentos para ações foram relevantes para os desdobramentos da Arte ao longo de tais décadas. O Grupo Rex, formado pelos artistas Wesley Duke Lee, Ge raldo de Barros e Nelson Leirner, realizou exposições, periódicos de arte independentes (o Rex Time), palestras, happenings e projeções de filmes entre 1966 e 1967. O grupo teve a participação também do professor da ECA/USP (Escola de Comunicação e Artes da Universidade de São Paulo) e artista Carlos Fajardo, que passou a lecionar nesta instituição a partir de 1996, tendo obtido o título de doutor em Poéticas Visuais em 1998. A artista brasileira Carla Zaccagnini, mestre em Poéticas Visuais também pela ECA-USP, observa nesse sentido que "a universidade proporciona ao artista um espaço para elaborar "um pensamento" ou "um discurso a respeito da produção" (RIBEIRO, s.d.).

A partir desses exemplos pontuais é possível perceber um pouco do quanto a figura do artista se inseriu gradual e crescentemente nos meios acadêmicos. Como analisa o professor Flávio Gonçalves do PPGAV da UFRGS:

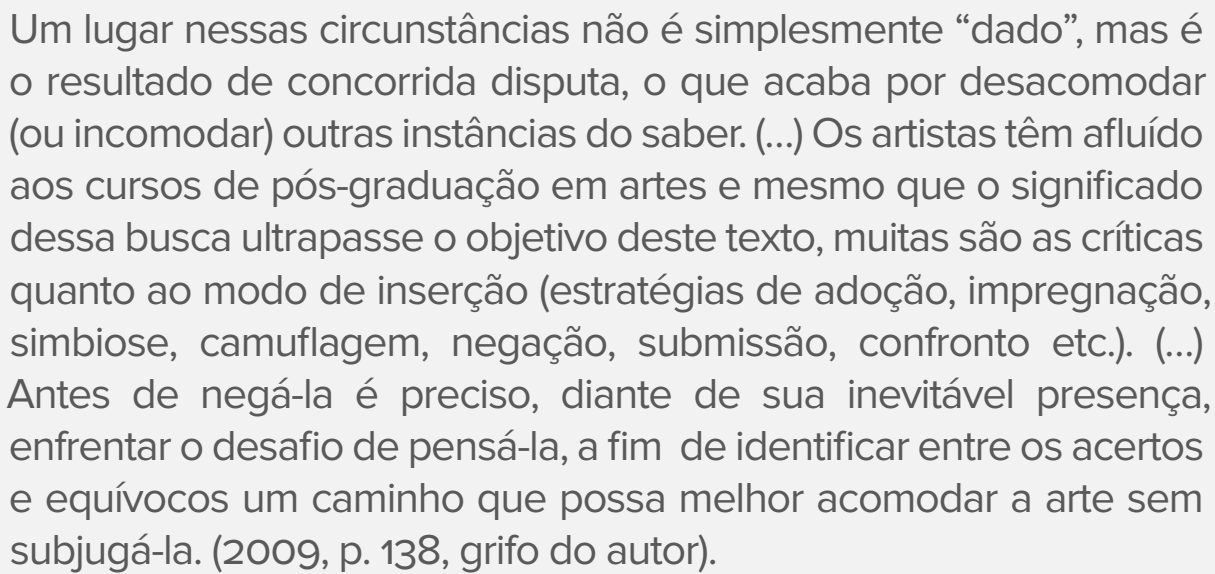

Parto deste entendimento quanto à pesquisa em Poéticas Visuais, sem deixar de observar as particularidades desta abordagem metodológica e acadêmica num processo que tem o inesperado, o sensível, o 
imprevisível e o imponderável em suas engrenagens de "funcionamento", pois envolve a criação artística. Para avançar na discussão e argumentação da pertinência em se constituir um processo de elaboração artística por meio das articulações próprias à uma pesquisa acadêmica, passo a expor algumas considerações e apontamentos a respeito de minha própria prática de pesquisa como artista e pintor na universidade ao longo dos últimos anos, na condição de "artista/pesquisador"

$\mathrm{Na}$ conjunção de elencar e definir conceitos com as atividades do trabalho de ateliê abracei a busca por alguma espécie de cientificidade (assumindo-se os paradoxos contidos nessa busca) durante o processo de criação de um trabalho em artes visuais. Assumir tais paradoxos de forma deliberada poderia ser interpretado como uma direção despropositada, ao levar-se em conta o quão inescrutável e imprevisível é a ação criadora. Contudo, tal pesquisa alinha-se com a postura de René Passeron, quando ele afirma que "reivindicamos a autonomia da poiética como reflexão sobre a conduta criadora” (2004, p. 10, grifo nosso).

Durante minhas pesquisas a noção de poiética foi instrumento teórico importante para a articulação entre a feitura prática e a reflexão textual. Segundo o autor, a poiética seria "a promoção filosófica das ciências da arte que se faz", entendendo-se poiética como "uma teoria filosófica da criação artística" (PASSERON apud GONÇALVES, 2009, p. 141-142). De modo que a poiética tem como foco "o reconhecimento da criação artística como processo em si, dentro do escopo de uma ciência da arte que parece se esforçar para marcar sua diferença em relação à outras, sobretudo a Estética" (GONÇALVES, 2009, p. 142). Um conceito que "trata de elucidar, tanto quanto é possível fazê-lo, o fenômeno da criação (...) a poiética será o que fizermos dela, nos limites de seu alcance, com a certeza ambiciosa de chegar a alguma verdade em um domínio reputado obscuro" (PASSERON, 2004, p. 10)

Numa progressiva elaboração teórica e reflexiva em constante in- tercâmbio com o trabalho de ateliê a compreensão foi a de que essa é uma postura que edifica a pesquisa em Poéticas Visuais. Nesse sentido é necessário esclarecer que a posição e o olhar de pesquisador do artista, que medita sobre sua produção prática simultaneamente a elaboração desta, não é o mesmo daquele da pesquisa sobre arte, que se faz por um olhar outro que não o do artista (como é o caso no campo da Estética ou da História e Crítica de Arte, por exemplo).

Em outras palavras, o artista, ao se dispor a percorrer uma pesquisa em Poéticas Visuais, opera no "lado de dentro" das Artes Visuais, pelo interior do seu processo criativo e criador. Enquanto o historiador ou o crítico analisa o campo das Artes pelo "lado de fora", perscrutando as obras, situações e biografias dos artistas tão próxima e intimamente quanto possível, mas inevitavelmente através de um olhar e experiência alheios ao processo mesmo da criação artística.

Desta maneira, pode-se pensar a elaboração da pesquisa em Poéticas Visuais como algo semelhante à um caderno de apontamentos do artista ou um "diário de bordo". Isto é, um lugar onde ele compila suas coleções de achados, estudos sobre outros artistas ou passagens que considera relevante na História da Arte, referências à obras de outros artistas, considerações sobre seus possíveis acertos ou equívocos, rotas e desvios durante o que imaginou fazer em sua prática e o que acabou fazendo de fato - tudo isto ao longo de seu processo de criação naquele momento.

Muitos artistas empreenderam algo do tipo ao longo da História da Arte. Como exemplos pontuais que compilam diversas reflexões de artistas sobre seus próprios trabalhos, obras e processos, podemos citar o livro Teorias da Arte Moderna organizado por Herschel Chipp (1988), que apresenta textos de artistas pontuais de movimentos como Pós-impressionismo, Fauvismo, Cubismo, Construtivismo, Dada, Surrealismo. Também o livro Art in theory, 1900-2000: an anthology of changing ideas organizado por Paul Wood e Charles Harrison (2002), que "mostram que a projeção 
modernista faliu também na divisão projetada entre o papel de artista e crítico, segundo a qual se supunha que "o artista fosse um 'fazedor desarticulado' em cujo nome o crítico apresentava sentidos e explicações inteligentes"'” (HARRISON apud PELED, 2012). E o mais recente deles, Escritos de Artistas: anos 60/70 organizado por Glória Ferreira e Cecilia Cotrim, no qual os textos dos artistas "não só se integram à poética de cada obra, como também invadem o domínio da crítica e da história da arte" (PELED, 2012).

Sem chegar a estabelecer uma categorização de escritos e textos de artistas - o que certamente extrapolaria o escopo deste artigo - podemos perceber que nessa seara há textos que surgem como ramificações do trabalho poético em si. Contudo, uma vez que expandem o universo no qual o artista transita, não se referindo direta ou obviamente ao seu trabalho e tendo estatuto autônomo de criação (seja como ficcionalizações ou ensaios ${ }^{3}$ ), esse tipo de texto parece estar numa condição distinta daquele que se coloca como um lugar de reflexão sobre a própria poética de criação do artista em seus meandros

Longe de qualquer intenção de se impor regras ou posturas dogmáticas no campo da pesquisa em Poéticas Visuais (o que não faria sentido dada a necessidade que o campo evoca quanto à definição pessoal da própria metodologia a ser seguida por cada artista, como abordarei a seguir), cabe ressaltar que o espírito de se fazer uma pesquisa nessa linha compreende em si o desejo do compartilhamento do conhecimento. O caminho de pesquisa (inevitavelmente claudicante, por vezes até mesmo paradoxal) do artista na articulação do pensamento formal e do pensamento poético implica - como se verifica em qualquer outro campo de pesquisa - dispor para seus leitores e observadores o acompanhamento e o resgate de sua própria caminhada.

Portanto, daí se origina e aí se fundamenta o rigor, a organização e a clareza esperadas na elaboração e na apresentação de uma pesquisa em Poéticas Visuais. Essas exigências fazem parte das formalidades universitárias que se impõe ao artista na elaboração claudicante e de tensão entre os lugares ocupados e transitados pela pesquisa em Poéticas. Nesse aspecto, conforme nos lembra a artista Carla Zaccagnini

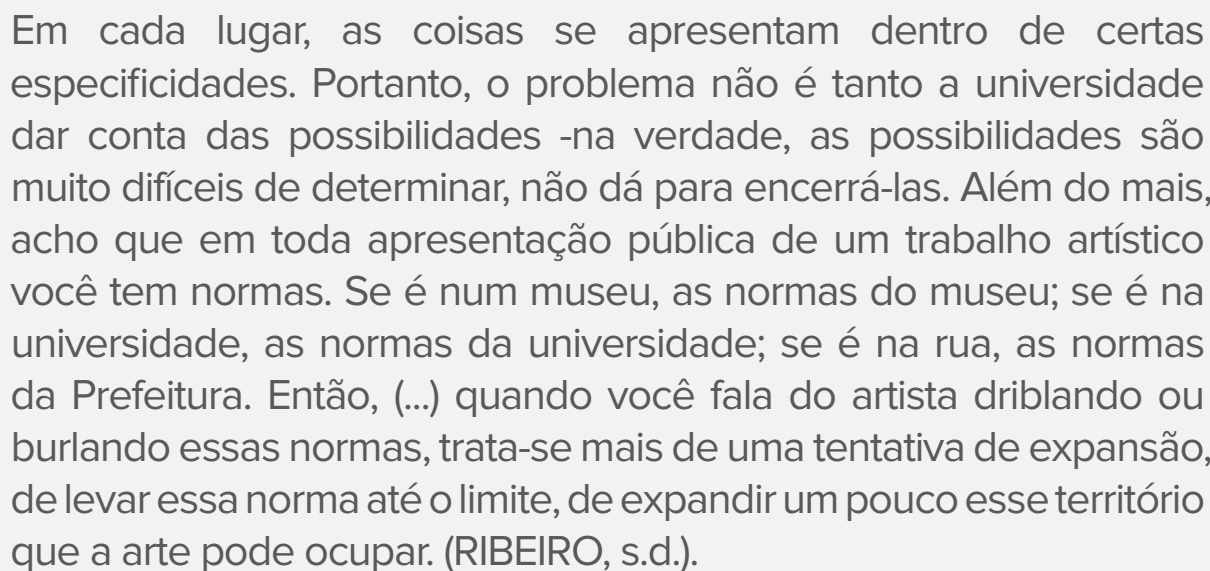

A despeito das formalidades acadêmicas, o método e a elaboração teórica tem seu princípio baseado em (tanto quanto é possível neste escopo) dar a ver o caminho percorrido pelo artista, em universalizar o conhecimento. Nesse sentido, não se deve deixar de notar a ressalva que aponta o também professor da linha de pesquisa em Poéticas, Yiftah Peled:

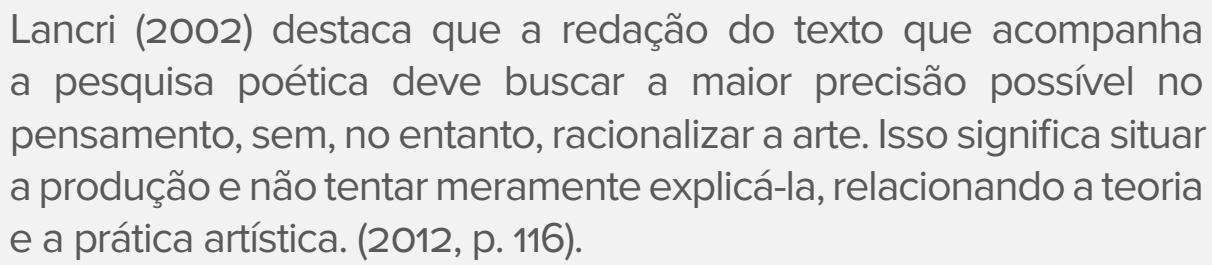

Ou seja, uma pesquisa em Poéticas Visuais é disposta como um procedimento realmente fértil para o artista quando este manipula a teoria como instrumento e alavanca em seu processo artístico e criativo. Em outras palavras, a universidade e os meandros teóricos colocam-se para os artistas como lugares de reflexão, meditação e autoquestionamento 
contínuo, no sentido de alavancar seus processos de trabalho, quando eles não se ocupam com uma explicação que teria a pretensão de ser uma espécie de tradução verbal daquilo que o objeto artístico já é por si e em si próprio.

Na articulação teórico-prática de Poéticas, como nos lembra Jean Lancri no mesmo texto que foi citado acima por Peled,

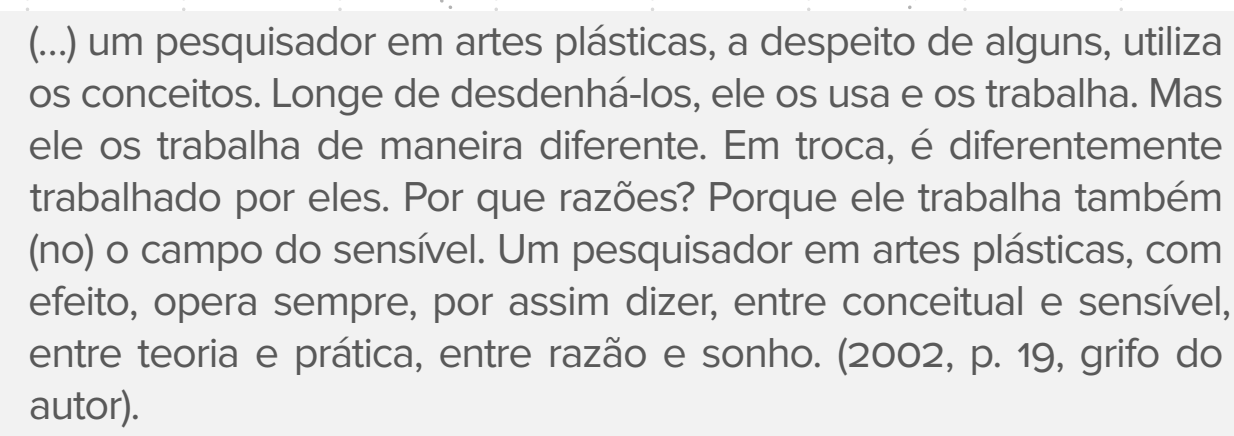

De modo que o artista/pesquisador é um pesquisador acadêmico com uma condição bastante particular, pois ele parte já do meio de uma prática própria de trabalho (LANCRI, 2002) para iniciar sua pesquisa. Ao contrário do pesquisador de outras áreas (e mesmo de outras linhas do campo das Artes Visuais), ele próprio inventa seu problema de pesquisa. Se propor a analisá-lo de modo aprofundado e sem se fazer concessões é definidor para o que será a continuidade desta prática. O "artista/pesquisador" assim parte para a "delimitação de seu objeto (ou de seu sujeito) de estudo, o que, de saída, vai condicionar sua estratégia” (Ibid., p. 21), ou seja, a sua metodologia de pesquisa.

Com efeito, dadas as mencionadas particularidades de seu objeto e de seu processo, cada artista/pesquisador precisa encontrar e moldar sua própria metodologia e seu modo específico de conduzir sua pesquisa teoricamente. Uma vez que
No início de uma pesquisa é comum serem levantadas uma série de questões relacionadas a como a tarefa deve ser abordada. Esse momento de dúvida, comum entre pesquisadores em geral, assume no artista/pesquisador uma dimensão peculiar, pois não está relacionada apenas a aplicação de modelos pré-estabelecidos, mas fundação de pressupostos metodológicos, que em outras áreas jă são de domínio do aluno de graduação. (GONÇALVES, 2009, p. 139).

Pensa nas relações entre imagem e palavra, está analisando um determinado discurso. Percebe a diferença entre os conceitos construídos e o movimento destes conceitos, quando sai com seus alunos e se colocam no chão para ver como se constrói uma linha. O quão delicado pode ser o entrecruzamento de linhas, e como pode ter liberdade em construir seus próprios pensamentos, inventando uma cartografia de sua escrita.

Para retornar à proposta deste artigo de expor e considerar minha própria prática como artista/pesquisador no sentido de melhor elucidar as especificidades do que acredito constituir e abarcar uma pesquisa em Poéticas Visuais, chamo a atenção para a mencionada importância da noção de poiética como instrumento teórico. Ao refletir a respeito dos desdobramentos ocorridos na minha própria produção pictórica em ateliê - o que por sua vez auxiliou a continuidade na configuração dessa produção -, a noção de poiética foi encontrada como recurso teórico que fez parte de minha metodologia, e não necessariamente estaria presente na metodologia de outro artista/pesquisador.

Além da poiética, outro conceito empregado por mim naquela metodologia em particular foi o de mestiçagem no contexto da arte contemporânea, tal como é analisado e considerado pela professora e teórica Icleia Cattani. A noção de mestiçagem foi igualmente ferramenta teórica auxiliar ao se considerar uma pesquisa que envolvia a feitura de uma pintura que empregou e integrou meios visuais diversos (cinema, vídeo e fotografia, no caso), mas que não mesclava suas visualidades de modo homogêneo, tampouco trabalhava tais visualidades de modo excludente. Uma vez que, 
conforme esclarece Cattani,

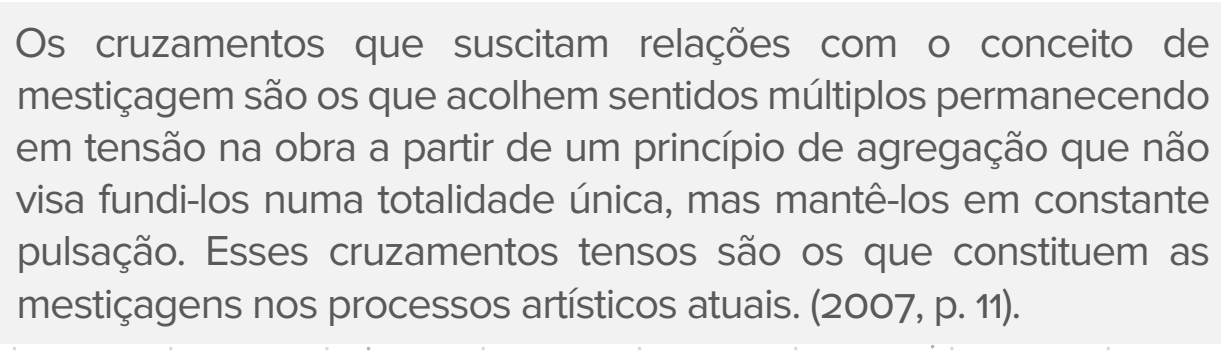

De modo que as articulações e registros dispostos pelo artista/pesquisador em cada caso procuram "encontrar uma metodologia de trabaIho (...) manter o espírito investigativo sistemático (...) ampliando a sensibilidade e a qualidade do processo criativo" (CATTANI, 2002, p. 39).

Assim, enfatiza-se novamente que "a pesquisa de arte buscará o rigor de análise que the permita qualificar-se como pesquisa, aliando-lhe, à sensibilidade do olhar, a profundidade da formação teórica" (Ibid., p. 38 , grifo do autor). Com efeito, no decorrer de meu processo criador e de construção pictórica, para constituir a pesquisa e sua metodologia operei incessante emprego de conceitos operatórios, densas análises e ferramentas teóricas auxiliares que provinham de outras áreas de conhecimento, como engrenagens no conjunto de ideias e desenvolvimentos do ateliê.

Este modo de ação e existência do artista através desta linha de pesquisa, para além do universo ensimesmado do artista, justifica-se no campo das Artes Visuais ao se considerar que

(...) só nos é possível pensar a arte através da obra e/ou do artista. (...) A posição de artista/autor pode passar, assim, de suspeita à privilegiada numa pesquisa quando pensamos na arte como uma da prática rística; a prososta. E tem-se com isso a experiência contradições. (GONCSALVES, 2009, p. 139).
Aí temos, em poucas linhas, uma definição do lugar que ocupa a pesquisa em Poéticas dentro do campo maior em que se insere. Vale ressaltar e complementar que, como já observado anteriormente, tal definição conceitua especificamente a pesquisa em Poéticas e não tem assim pretensão de abranger o escopo completo dos escritos de artista (que se estende por variações como a do texto como manifesto de um grupo ou ou de um movimento, por exemplo).

Quanto às contradições mencionadas por Gonçalves, volto-me mais uma vez ao exemplo pessoal. Minha tese de doutorado em Poéticas Visuais (2013) pautou-se pelos paradoxos contidos nas aproximações e junções empreendidas pelo processo prático de trabalho, bem como na constatação de contradições resultantes das mencionadas buscas por rigor e cientificidade numa criação sensível.

0 primeiro paradoxo enunciado naquela pesquisa dizia respeito exatamente a esta postura. Entendo que, nesse caso, mesmo a abordagem rigorosa demonstra um descompasso, em seus planejamentos e análises, com os fatos do trabalho, seus resultados e sua potência. O que se evidencia pelo viés do inesperado, do incontrolável, do que escapa à compreensão plena e literal.

A partir daí, assumi tal paradoxo porque a percepção foi a de que, a partir da rebuscada tessitura presente na metodologia proposta, criaram-se as condições possíveis e necessárias para que o trabalho acontecesse. Em outras palavras, essa elaboração metodológica particular revelou-se requisito para que o trabalho prático surgisse, fazendo com que este ganhasse autonomia própria em relação à metodologia e preceitos traçados que o originaram. Acredito também que "lidar com o arcabouço metodológico poderá permitir que a invenção e a fruição convivam com a clareza e o rigor, necessários à produção e à transmissão de conhecimento" (CATTANI, 2002, p. 49). Ademais, essa busca metodológica sistemática ecoou as organizações de como se dava a feitura em ateliê dos 
processos práticos da pesquisa.

Procurei enfatizar naquela pesquisa, portanto, que a condição primordial da elaboração textual era a de ser colocada em trabalho com a pintura, com os propósitos de refletir sobre essa execução e, simultaneamente, analisar essa feitura em profundidade, através de um processo de distanciamento do ato criador, a despeito do quão errante e repleto de bifurcações tal percurso possa ser. Cabe esclarecer que ao mencionar distanciamento nesse contexto o faço no mesmo sentido que indica Gonçalves, ao considerar que

O artista/pesquisador se coloca como um observador implicado em seu objeto, com o dever de dele distanciar-se o suficiente para criar "espaço" para a observação e a interpretação, num vai e vem semelhante ao que exercita quando da fatura do seu trabalho. Esse espaço é tencionado pela rememoração da experiência, pela autocrítica e, por conseguinte, pela invenção. (GONÇALVES, 2009, p. 139).

Ou seja, como menciona Jean Lancri, situar-se nessa distância que procura racionalizar aquilo que é da esfera do sonho (2002). Postura descrita por Gerhard Richter como artista e pintor, em um texto seu de 1966:

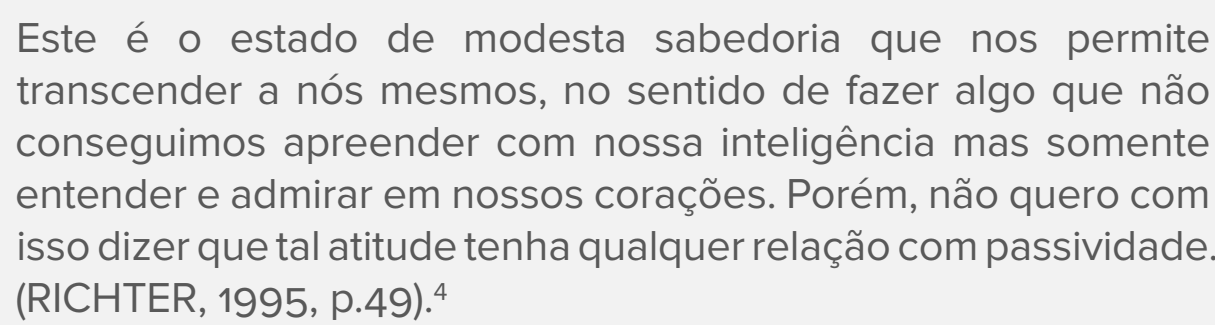

Durante a elaboração de minhas pesquisas a intenção foi a de se trabalhar com este cuidado metodológico, visando uma autonomia da pintura em sua feitura, em sua execução e acontecimento próprios.
Trata-se de uma postura que desejava deixar a pintura acontecer pelos seus próprios meandros de instauração, imprevisíveis para o pintor. $\mathrm{O}$ acontecimento-pintura depende, portanto, dessa negociação constante entre os desígnios do pintor e a autonomia pictórica.

De todo modo, mesmo que o conjunto de escolhas de trabalho tenha ocorrido em certa medida, e inerentemente, de forma intuitiva, suas ações foram fertilizadas a partir das condições instauradas no direcionamento, especificidades e repertório decorrentes do desenvolvimento daquela pesquisa em Poéticas Visuais. Nota-se aí o imbricamento e trânsito entre teoria e prática em Poéticas, dado que essas pesquisas, por sua vez, se deram através da consideração de maneira sistemática das reflexões, registros e estudos teóricos elaborados conjuntamente à prática em ateliê.

Foram abordados, em diversos momentos nos textos dessas pesquisas, campos distintos e eventualmente distantes da Arte (tais como sociologia e filosofia, por exemplo). Mas deve ser ressaltado que estes foram considerados sempre pela ótica e viés específicos do problema instaurado pela pesquisa.

Aí reside outro aspecto que delineia a pesquisa em Poéticas, e que podemos chamar de "fio condutor". Uma vez que este tipo de pesquisa tem como objetivo principal debruçar-se sobre o processo de criação, são as exigências e as demandas desse processo que acabam por nortear suas reflexões (mesmo que algumas dessas reflexões instaurem-se como desvios ou apêndices a partir do processo - e nesse contexto a expressão "a partir de" é chave). É este norte que chamo aqui de "fio condutor", e que pode nos ajudar a visualizar a relevância dos desenvolvimentos que vão sendo dispostos ao longo da elaboração da pesquisa.

Os fragmentos destacados e correlacionados entre si nas páginas dos escritos resultantes das pesquisas apontaram situações, 
elucidaram conceitos e noções e, até mesmo, aprofundaram dúvidas incontornáveis no decorrer daqueles percursos. Assim, nos seus momentos de desfecho empreendi apreciação e recapitulação de todo o trabalho realizado e das tessituras de suas construções.

Ao alcançar um momento de maturidade daquela pintura como o percebido ao fim do doutorado, alcancei também uma compreensão dela que incitava sua própria continuidade, sem que esta se esgotasse - na verdade, o que se evocava era exatamente o oposto de qualquer esgotamento. Contudo, isto não significa que houvesse qualquer segurança ou previsibilidade nesta continuidade. Nesse sentido, a sensação parece ser semelhante àquela manifestada por Gerhard Richter, quando o pintor alude ao permanente enigma que constitui o ato pictórico:

Richter nunca deu lugar à tentação de pensar que pudesse ser possível planejar o resultado de sua pintura, ou controlar sua execução. Seus apontamentos contêm muitas observações do modo como, ao alcançar certo estágio, ele teve que "destruir" ou "salvar" um trabalho. No processo de criação, os quadros desenvolvem uma dinâmica própria que frequentemente surpreendem o próprio artista, e mesmo que ele possa intervir para fazer correções, nunca está totalmente no domíni intervir "Levou um bom tempo" Gerhard Richter finalmente admite para si próprio "até que eu me desse conta de que o que eu faço - a experimentação desesperada, todo o conjunto de dificuldades - é exatamente o que todos eles fazem: esta é a natureza do trabalho. Isto é pintura. (ELGER, 2001, p. 109-110). ${ }^{5}$

Procurei igualmente alcançar ao longo das páginas de todo volume de minha tese um entendimento da elaboração e discussão teórica como elemento motor deste tipo de pesquisa. Juntamente com a conclusão de meu Estágio Pós-Doutoral, essas são as experiências que busco compartilhar neste artigo, ao menos tanto quanto é possível nesse sentido. Posto que ao longo desses caminhos ficou claro para mim que $o$ ato de fazer pesquisa em artes contempla, em última instância, apreender e descobrir aquilo que é e que configura a própria pesquisa em Poéticas Visuais.

\section{REFERÊNCIA BIBLIOGRÁFICA}

CATTANI, Icleia Borsa. "Arte Contemporânea: O lugar da pesquisa”. In: BRITES, Blanca; TESSLER, Elida (Org.). O meio como ponto zero: metodologia da pesquisa em artes plásticas. Porto Alegre: Editora da UFRGS, 2002, p. 35-50.

. (Org.). Mestiçagens na arte contemporânea. Porto Alegre: Editora da UFRGS, 2007.

CHIPP, Herschel B. Teorias da arte moderna. 4a edição. São Paulo: Martins Fontes, 1988.

ELGER, Dietmar. "Failure as an Artistic Agenda: The Paintings of Gerhard Richter" In: W Warhol, Polke, Richter: In the Power of Painting 1. Londres: Thames and Hudson, 2001, p. 109-117.

FERREIRA, Glória; COTRIM, Cecilia. (Org.). Escritos de artistas: anos 60/70. Rio de Janeiro: Jorge Zahar, 2006

GONÇALVES, Flávio. "Um argumento frágil”. In: Porto Arte: Revista de Artes Visuais, Porto Alegre: Instituto de Artes/UFRGS, v.16 n.27, p. 137-145, nov. 2009.

HARRISON, Charles; WOOD, Paul. Art in theory, 1900-2000: an anthology of changing ideas. 2a Edição. Londres: Blackwell Publishing, 2002.

LANCRI, Jean. "Colóquio sobre a metodologia da pesquisa em artes plásticas na universidade" In: BRITES, Blanca; TESSLER, Elida (Org). O meio como universidade." In. BRITES, Blanca; TESSLER, Elida (Org.). O meio como ponto zero: p. 15-33.

MELLO, Ricardo Perufo. "A Carne da Imagem: uma poética de trânsitos do cinema e da fotografia através da pintura". In: 240 ENCONTRO DA ASSOCIAÇÃO

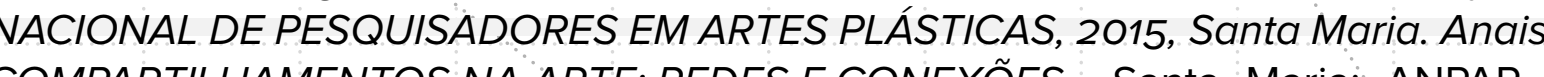
COMPARTLHAMENTOS NA ARTE: REDES E CONEXOES. San Manla. ANPAP Associação Nacional de Pesquisadores em Artes C Plásticas, 2015, P. 1594-1609.

A Carne da Imagem: uma produção poética de trânsitos do cinema e da fotografia através da pintura. Relatório final de Estágio Pós-Doutoral - PPGARTES, Universidade Federal do Pará, UFPA, 2016. 
Interferências entre transposições: uma poética pictórica de acumulação e adensamento de imagens videográficas. Dissertação (Mestrado em Artes Visuais) Instituto de Artes, Universidade Federal do Rio Grande do Sul, Porto Alegre, 2008

Rarefação e construção pictórica: paradoxos imagéticos (mestiçagens contidas na temporalidade de uma imagem videográfica rarefeita). Tese (Doutorado em Artes Visuais) - Instituto de Artes, Universidade Federal do Rio Grande do Sul, Porto Alegre, 2013.

"Rarefação: paradoxos imagéticos (mestiçagens contidas na poética pictórica de uma imagem videográfica rarefeita". In: Porto Arte: Revista de Artes Visuais, Porto Alegre: Instituto de Artes/UFRGS, v.18 n.31, p. 73-80, nov. 2011.

PASSERON, René. "A poiética em questão". In: Porto Arte: Revista de Artes Visuais, Porto Alegre: Instituto de Artes/UFRGS, v.13 n.21, p. 9-15, jul. 2004

"Da Estética a Poiética". In: Porto Arte: Revista de Artes Visuais, Porto Alegre: Instituto de Artes/UFRGS, v. 8, n.15, p. 103-116, nov. 1997

PELED, Yiftah. "Metodologia em Poéticas Visuais". In: Porto Arte: Revista de Artes Visuais, Porto Alegre: Instituto de Artes/UFRGS, v.19 n.33, p. 115-132, nov. 2012

PRINCE, Richard. Collected writings. Nova York: Foggy Notion Books, 2011

RIBEIRO, José Augusto. Arte e universidade: como foi o encontro Trópico na Pinacoteca. Dossiê debate/em obras. s.d. Disponível em: <http://p.php.uol.com.br/ tropico/html/textos/2378,1.shl>. Acesso em: 27 jan. 2017.

RICHTER, Gerhard. "Text for exhibition catalogue, Galerie h, Hanover, 1966". In

WOOD, Paul. Arte conceitual. São Paulo: Cosac \& Naify, 2002. (Movimentos da Arte moderna). 